\title{
Numerical design of a new forging press drive incorporating non-circular gears
}

E Doege, J Meinen, T Neumaier* and M Schaprian

Institute for Metal Forming and Metal Forming Machine Tools, University of Hanover, Germany

\begin{abstract}
Manufacturing processes as well as products have to be improved continually to meet all the requirements of international competition. Along with economic demands, changing consumer and environmental legislation lead to increased pressure for new and advanced products and processes. Consequently, the forging industry continually tries to improve hot forging processes. Precision hot forging technology, used for the production of connecting rods, bevel gears, straight planet gears, helical gears, clutch gearing or constant velocity joints, has been improved constantly [1-3]. Precision forging is carried out with closed dies in order to guarantee the continuous quality of the workpiece and to avoid possible damage to the forged parts by clipping or piercing operations. Many variables influence the quality of the final product and the economics of the process, especially the workpiece temperature, the die temperature and the pressure dwell time. High workpiece temperatures lead to high temperatures on the surface of the dies. Therefore, the temperature load depends directly on the pressure dwell time. Excessive temperature loads inevitably lead to damage of the dies [4]. This article presents a numerical study of a new press concept using non-circular gears in the drive mechanism. The new press kinematics result in a reduced pressure dwell time in comparison with a conventional press kinematic.
\end{abstract}

Keywords: metal forming, finite element simulation, thermal die loading, drive mechanism, noncircular gears

\section{NOTATION}

a centre distance

$a_{m}, b_{m} \quad$ coefficients of Fourier series

$A$ surface area of the die

$C \quad$ quality of the transmission function regarding kinematic demands

$e \quad$ distance between the centre and the pivot of an eccentrically mounted circular gear

$i(\varphi) \quad$ transmission ratio as a function of the driving angle

$n \quad$ number of the cycle

$\dot{q} \quad$ flux

$Q \quad$ quantity of heat

$r_{1}(\varphi) \quad$ pitch curve radius of the driving gear as a function of the driving angle

$r_{2}(\varphi) \quad$ pitch curve radius of the driven gear as a function of the driving angle

$R \quad$ radius of a circular gear

$\begin{array}{ll}s & \text { ram stroke } \\ T_{\mathrm{die}} & \begin{array}{l}\text { local temperature of the tool } \\ T_{\mathrm{wp}}\end{array} \\ v_{\mathrm{s}} & \begin{array}{l}\text { local surface temperature of the workpiece } \\ \text { slide velocity }\end{array} \\ \uparrow & \text { record of Fourier coefficients } \\ \alpha_{\mathrm{tr}} & \begin{array}{l}\text { heat transmission coefficient } \\ \tau\end{array} \\ \varphi & \begin{array}{l}\text { cycle time } \\ \text { angle of the driving gear }\end{array} \\ \psi & \text { angle of the driven gear }\end{array}$

\section{PRECISION FORGING}

Owing to its working principle and the higher accuracy of parts, closed-die hot forging calls for higher requirements on process parameters and tool technology. Figure 1 shows the concept of the closed-die forging of a helical gear wheel. Closed-die forging is mostly used for the manufacturing of near net shape or net shape parts by precision forging. The punch or additional closing elements close the die during the deformation. To operate the closing elements, multi-acting presses, spring assemblies or separate closing devices are needed to provide the necessary closing pressure.
The MS was received on 14 March 2000 and was accepted after revision for publication on 30 June 2000.

*Corresponding author: IFUM, Universität Hannover, Welfengarten 1A, D-30167 Hannover, Germany. 


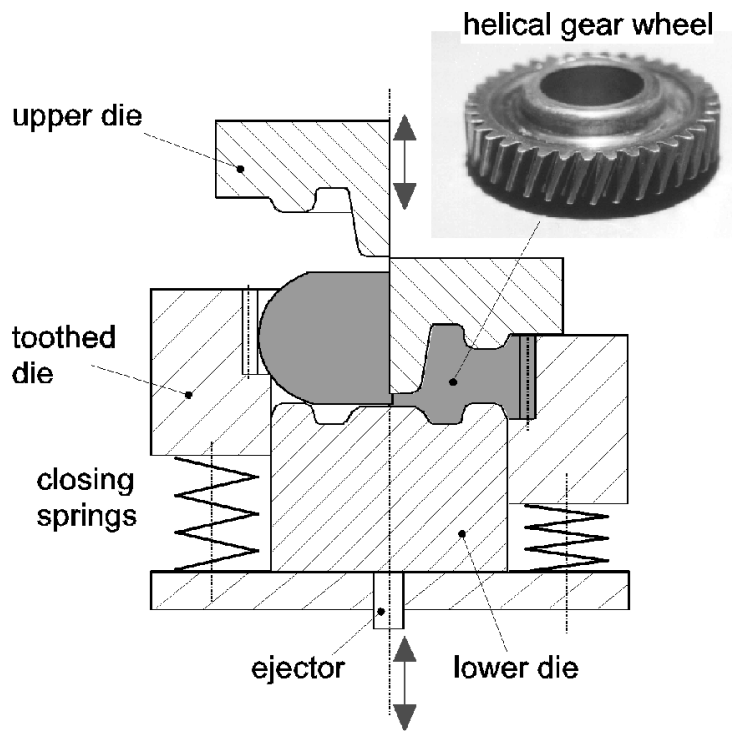

Fig. 1 Closed-die technology for the forging of a helical gear wheel

Divided dies or additional closing elements are needed if the punch is not able to close the die because of radial form elements such as helical gearings. Horizontally divided dies have the advantage that the closing load can easily be provided by the ram movement combined with spring assemblies. Vertically divided dies, which are necessary for the ejection of parts with undercuts, such as clutch gearings or constant velocity joints, need special devices for the transformation of vertical press loads into horizontal closing loads when used in a single-acting press. An alternative is the multiacting press, which is already used for thixoforming and hydroforming, although the ram velocity is often not fast enough for use in hot forging processes.
The quality of the precision forged parts reaches the ISO standard IT 7-9. Typical forging temperatures are between 1100 and $1280^{\circ} \mathrm{C}$ for steel materials.

\section{NEW PRESS CONCEPT IN PRECISION FORGING}

An increasing number of precision forging applications in the automotive industry have shown the limitations of conventional forging machines. Particularly for requirements such as reliable closing of the dies, short pressure dwell, constant energy distribution, overload protection and process integrated quality control, new concepts in hot forging machines are being developed continually. Based on the technological requirements for economic precision hot forging processes, IFUM has developed an innovative press concept $[\mathbf{5}, \mathbf{6}]$. The concept is based on a mechanical press with non-circular gears in the drive mechanism (Fig. 2) to guarantee minimum pressure dwell time and, by this, a lower thermal tool load.

\subsection{Optimization of the ram kinematics for the precision forging press}

Figure 2 shows the calculated optimized kinematics of a precision forging press in comparison with a conventional crank drive. The cycle time of both press drives is $1.0 \mathrm{~s}(60$ strokes $/ \mathrm{min})$, whereas every second stroke is an idle one in order to prolong the cooling time. With a forming section of $20 \mathrm{~mm}$, the resulting pressure dwell time of the conventional drive is $75 \mathrm{~ms}$. By using non-circular gears, it is decreased to $39 \mathrm{~ms}$.

The varying transmission ratio, $i(\varphi)$, of the non-circular gears [5] causes a non-uniform angular velocity, $\dot{\psi}(\varphi)$, of

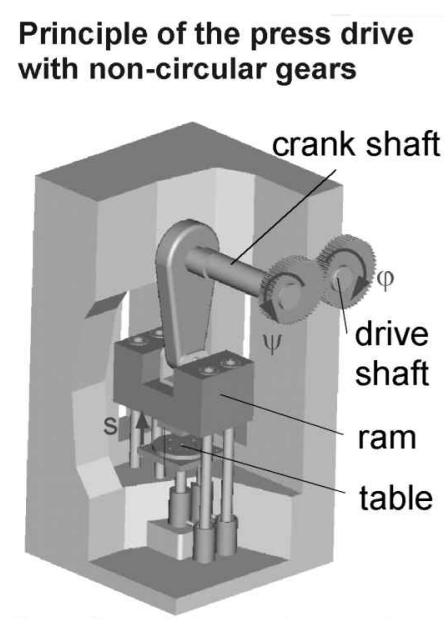

Benefits of the optimized kinematics - reduced pressure dwell time

- increased cooling time

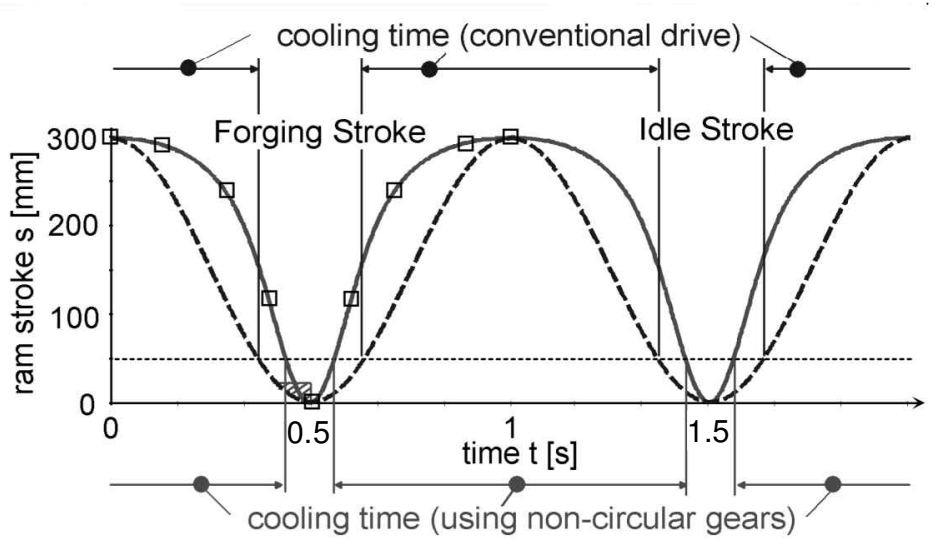

ram stroke time course of conventional crank drive optimized course by usage demands on of non-circular gears pressure dwell time

the ram kinematics

Fig. 2 Optimized kinematics of a forging press drive with non-circular gears 


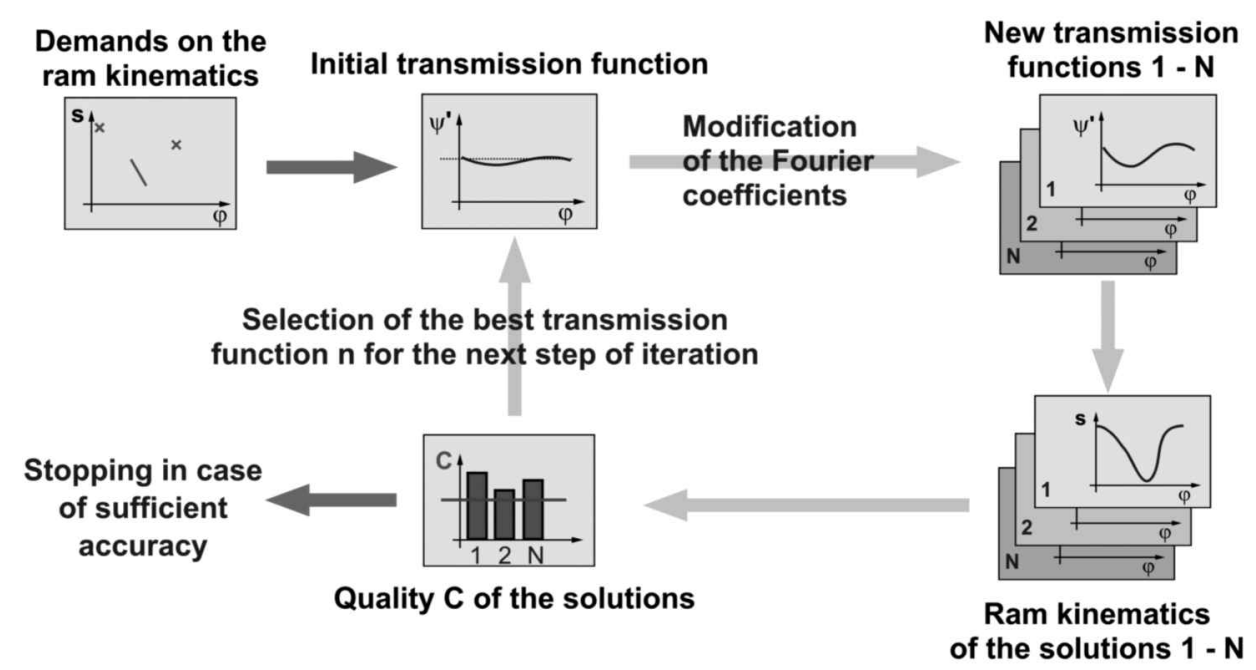

Fig. 3 Determination of the transmission function by a Fourier series with a limited number of harmonic waves

the crankshaft, a decreased ram velocity, $\dot{s}$, within the upper stroke area and an increased one within the forming area. The variable pitch curve radii, $r_{1}(\varphi)$ and $r_{2}(\psi)$, of the non-circular gears are determined by the required course of the transmission ratio $i$ and therefore the ram kinematics:

$$
i(\varphi)=\frac{\mathrm{d} \varphi}{\mathrm{d} \psi}=\frac{1}{\psi^{\prime}(\varphi)}=-\frac{r_{2}(\varphi)}{r_{1}(\varphi)}
$$

With a given constant centre distance

$$
a=\text { constant }=r_{1}(\varphi)+r_{2}(\varphi)
$$

the transmission function $\psi^{\prime}(\varphi)$ describes the relation between the pitch curves of the non-circular gears.

In order to fulfil the requested demands on the ram kinematics (Fig. 2), the transmission function of the non-circular gears has to be suitably adapted. This function is determined as a Fourier series with a limited number, $M$, of harmonic waves:

$$
\psi^{\prime}(\varphi)=\frac{\mathrm{d} \psi}{\mathrm{d} \varphi}=1+\sum_{m=1}^{M}\left[m b_{m} \cos (m \varphi)-m a_{m} \sin (m \varphi)\right]
$$

In order to determine the Fourier coefficient record $=\left(a_{1}, \ldots, a_{M}, b_{1}, \ldots, b_{M}\right)$ so that the resulting ram kinematics fits the demands, an iterative genetic algorithm has been realized (Fig. 3).

Firstly, an initial coefficient record ${ }^{\mathrm{p} 0}$ is estimated from the given kinematic demands by ${ }^{\uparrow}$ regression of a fifth-degree polynomial over all demands and subsequent determination of its Fourier coefficients. By randomized change of single coefficients $a_{m}$ and $b_{m}$ and interchange of coefficients, the next generation of $N$ coefficient records $\mathrm{p}^{\mathrm{p}}=\left(a_{1}, \ldots, a_{M}, b_{1}, \ldots, b_{M}\right), \quad n=$ $1, \ldots, N$ is generated. Then, the resulting ram stroke functions, $s_{n}^{\mathrm{p}}(\varphi)$, are determined by means of integration of $\psi^{\prime}(\varphi)_{n}^{\mathrm{p}}$ and the following consideration of the crank drive.
The quality, $C_{n}^{\mathrm{p}}$, of the transmission functions generated by the records $\underset{\uparrow^{n}}{\mathrm{p}}$ is determined by calculation of the difference to the predetermined kinematic demands and several other conditions such as minimization of the ram acceleration. The $\tilde{n}$ records $\underset{\uparrow^{n}}{\mathrm{p}}$ with the best quality are selected in order to generate the next generation, $\underset{\uparrow^{n}}{\mathrm{p}+1}$, of coefficient records by randomized modification. The iteration is stopped when the accuracy of the solution is sufficient, which is indicated by the quality, $C_{n}^{\mathrm{p}}$, of a solution falling below a predetermined value and a simultaneously slow rate of improvement in quality during a certain number of iteration steps.

Figure 4 shows the pair of non-circular gears calculated for the kinematic demands shown in Fig. 2. Since the angular velocity is variable owing to the changing transmission ratio, the course of the slide velocity as an important parameter for the wear of the gears is different for every pair of teeth. In order to obtain a sufficient load-carrying capacity, a module of $20 \mathrm{~mm}$ and a teeth number of 72 have been chosen.

\subsection{Optimization of the shape of the non-circular gears}

Since the shape of the driving gear is very similar to a circle, it is possible to obtain similar ram kinematics with an eccentrically mounted circular driving gear combined with a driven gear with a non-circular pitch curve. Such a pair of gears may be more economically manufactured than two gears with non-circular shapes.

The radius, $r_{1}(\varphi)$, of an eccentrically mounted circular gear is

$$
r_{1}(\varphi)=R\left[\varepsilon \cos \varphi+\sqrt{\varepsilon^{2}\left(\cos ^{2} \varphi-1\right)+1}\right]
$$

where $\varepsilon=e / R, R$ is the radius and $e$ is the distance between the centre and the pivot of the circle (Fig. 5) [7]. 

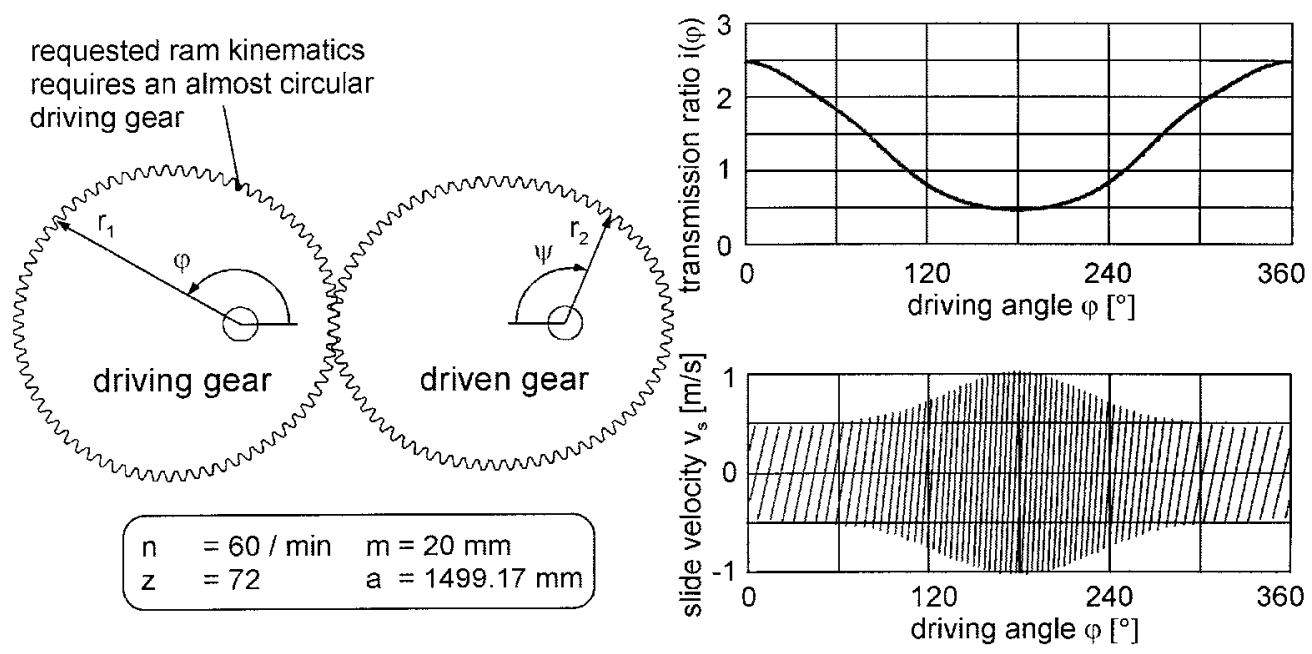

Fig. 4 Characteristics of the non-circular gears calculated by a Fourier series

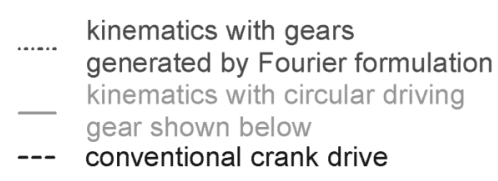

driving gear: eccentrically mounted circular gear

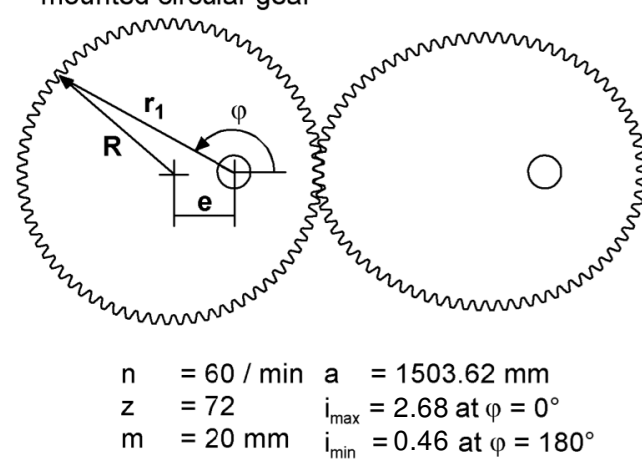

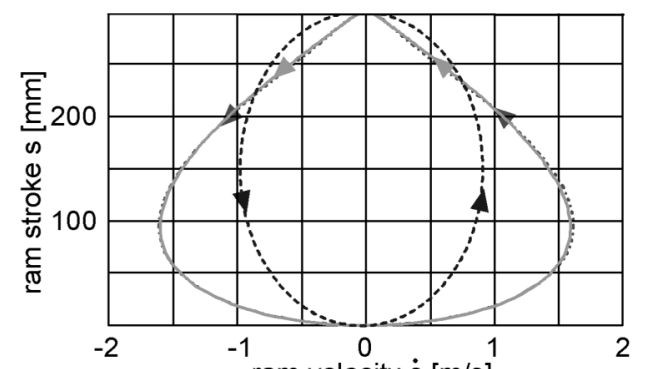

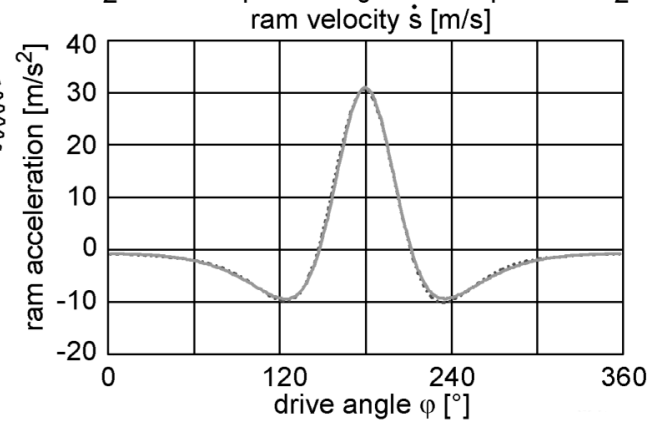

Fig. 5 Use of an eccentrically mounted circular gear for realization of ram kinematics

The transmission ratio is

$$
\frac{\mathrm{d} \psi}{\mathrm{d} \varphi}=-\frac{R\left[\varepsilon \cos \varphi+\sqrt{\varepsilon^{2}\left(\cos ^{2} \varphi-1\right)+1}\right]}{a-R\left[\varepsilon \cos \varphi+\sqrt{\varepsilon^{2}\left(\cos ^{2} \varphi-1\right)+1}\right]}
$$

In order to achieve an average transmission ratio of 1 and therefore closed pitch curves with identical circumferences, the condition

$$
\int_{\varphi=0}^{2 \pi} \psi(\varphi) \mathrm{d} \varphi=2 \pi
$$

has to be fulfilled [8]. For a given ratio $\varepsilon$, the centre distance has to be determined by solving this nonlinear equation.

Figure 5 shows a pair of gears with an eccentrically mounted driving gear, which realizes similar ram kinematics as the first pair of gears. The ram velocity as well as the acceleration only show a negligible difference to the original course. Owing to the changed shape and therefore changed circumference of the gears, the centre distance for an identical number of teeth and an identical module has changed to $1503.62 \mathrm{~mm}$.

In order to simplify the design of non-circular gears for press manufacturers, a PC program has been developed at IFUM. For a given set of kinematics it offers the possibility of calculating the shape of the pitch curves and teeth as well as other parameters including loadcarrying capacity and slide velocity.

\section{FINITE ELEMENT SIMULATION OF THE THERMAL DIE LOADING}

After the design of the press drive, the effects of the optimized kinematics on the thermal die loading should 
be examined. Therefore, finite element (FE) simulations have been performed in order to compare the different forming velocities and pressure dwells of a conventional crank drive and this newly proposed press drive.

A survey of the developments in metal forming simulation is given in the literature [9-11]. For the prediction or optimization of the material flow, an FE simulation with rigid dies is often sufficient. For estimation of process safety, knowledge of the die loading is required. In this case meshing of the dies with finite elements is also necessary. Some FE packages allow the simulation of forming processes with deformable dies and workpiece. The contact processor couples the boundary and transient conditions between the die and the workpiece. The thermomechanical deformations of the dies and their influence on the material flow can then be considered in a coupled forming simulation. Today, a coupled FE simulation using deformable dies for complex threedimensional FE models needs substantially longer CPU (central processing unit) time than with rigid dies. Therefore, the IFUM has developed a software tool that uses an uncoupled calculation of the workpiece and dies with FORGE3 for the mechanical model and MSC.MARC for the thermal analysis [12].

\subsection{Strategy of an uncoupled FE simulation}

At IFUM, helical gear wheels have been formed in a precision forging process. Characteristics for this process are the high local stresses in the dies. For this reason, the thermal die loading due to the forging process was investigated by the uncoupled method (Fig. 6). Firstly, an FE simulation of the forging process was performed with rigid dies. This simulation was performed with the commercial FE package FORGE3. The thermal fluxes into the rigid dies were then determined during this simulation. Subsequent calculation of the thermal die loading was performed with the previously determined external fluxes. The split nodal fluxes are brought on to the meshed dies as boundary conditions. This strategy leads to short CPU times. A previous investigation of a three-dimensional FE simulation of an orbital forging process resulted in a reduction in CPU time of about 50 per cent in comparison with the coupled method [12].

\subsection{FE simulation of the forging process and the thermal die loading}

To collect information about the thermal die loading as a result of the hot forging process for both press kinematics, uncoupled FE simulations were executed for the example of a helical gear wheel. In the first step, simulations with rigid dies were performed with FORGE3 for the non-circular and the conventional press kinematics (see Fig. 2). For both cases, the billet temperature was $1200^{\circ} \mathrm{C}$. The heat transfer coefficient for contact between the two surfaces was constant $\alpha_{\text {cont }}=25 \mathrm{~mW} / \mathrm{mm}^{2} \mathrm{~K}$.

To reduce the CPU time further, only a segment of the helical gear was modelled. Figure 7 shows the material flow and the temperature distribution of the thermomechanical simulation with FORGE3. Significant differences in temperature can be seen at the top of the tools and at the reliefs. The surface temperature of the conventionally forged part at the end of the forging process is $100-150 \mathrm{~K}$ lower than for the part that is forged with a non-circular gear drive unit. This effect becomes important when a heat treatment is to be integrated directly after the forging process to make use of the forging temperature.

The flux is determined as follows:

$$
\dot{q}=\frac{\mathrm{d}}{\mathrm{d} t} \frac{Q}{A}
$$

where

$$
\begin{aligned}
& Q=\text { quantity of heat } \\
& A=\text { surface area of the die }
\end{aligned}
$$

During the FE simulation with rigid tools, the fluxes, $\dot{q}$, have to be determined at the surface. In the second step, the calculated heat flow into the lower die is transferred to an FE model with meshed dies. To determine the evolution of heat into the die of more than one forging

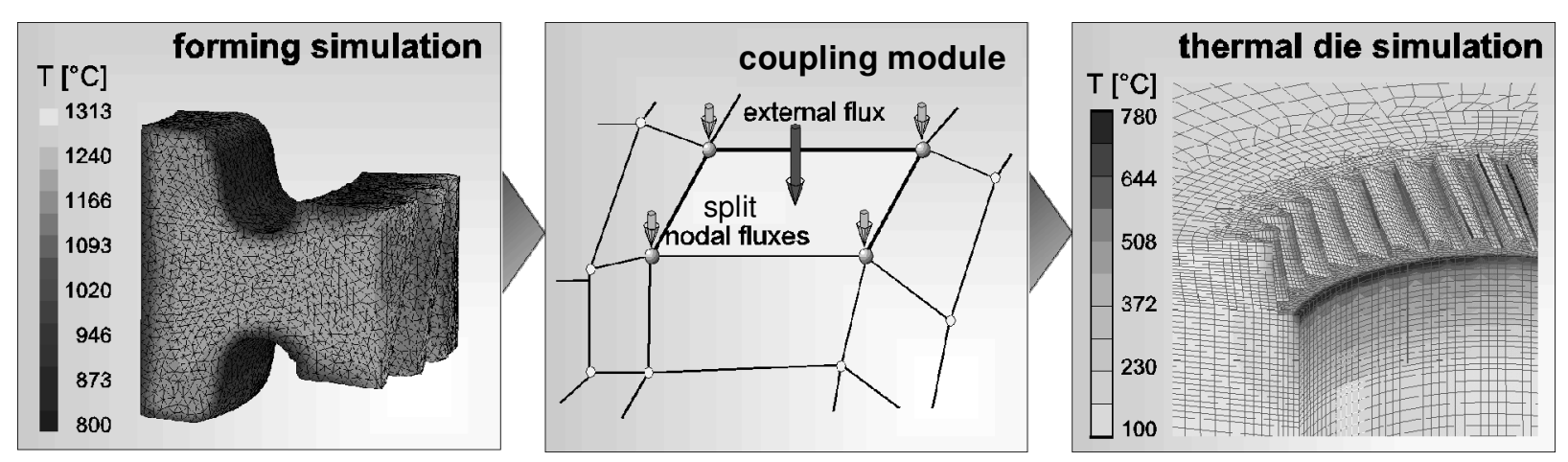

Fig. 6 Strategy of an uncoupled FE simulation 


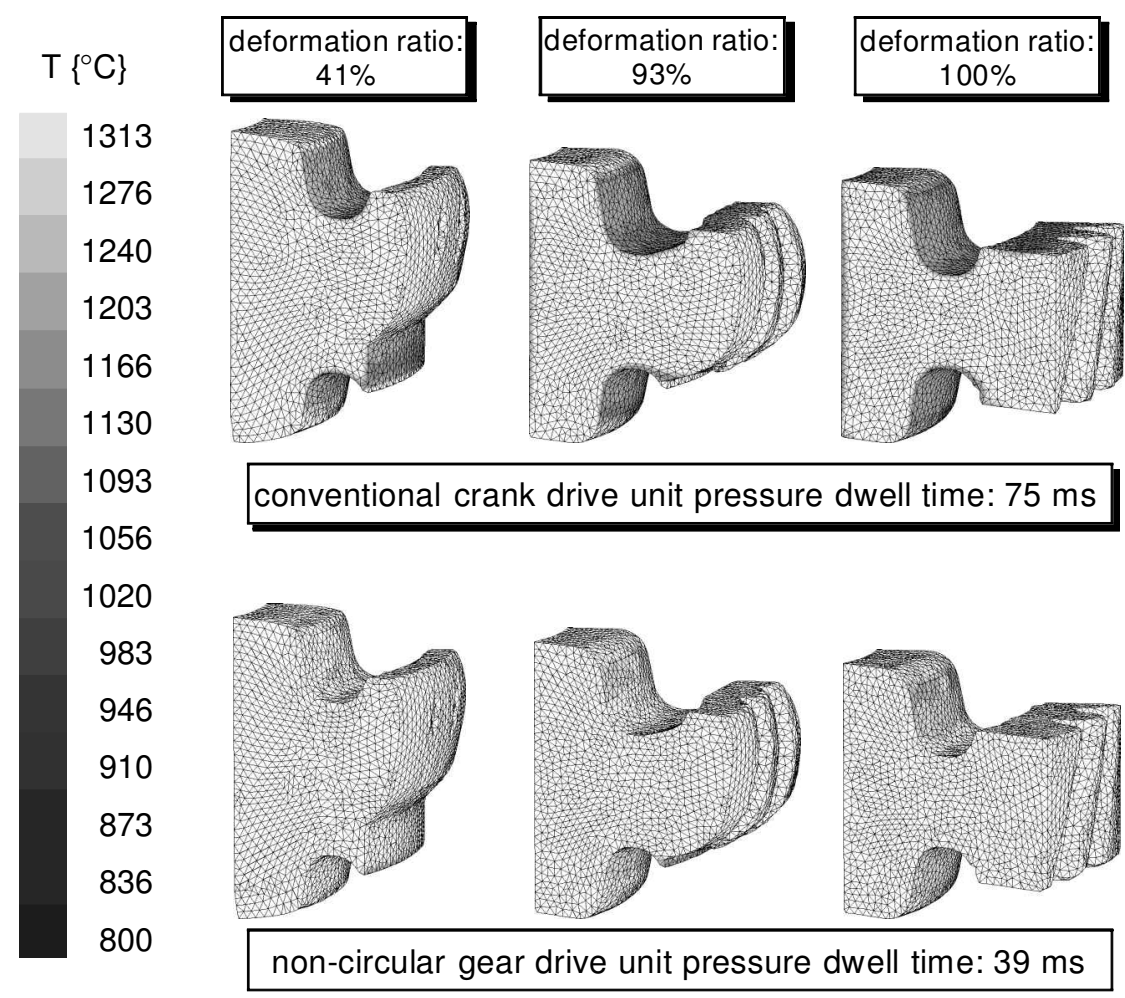

Fig. 7 Simulated material flow and temperature distribution at different deformation ratios with FORGE3 in a thermomechanical simulation (initial billet temperature $1200^{\circ} \mathrm{C}$ )

stroke, the following computation formula is used:

$$
\dot{q}_{n}(t)=\dot{q}_{0}(t-n \tau) \frac{T_{\mathrm{wp}}(t-n \tau)-T_{\mathrm{die}}(t)}{T_{\mathrm{wp}}(t-n \tau)-T_{\mathrm{die}}(t-n \tau)}
$$

where

$\dot{q}_{0}=\alpha_{\mathrm{tr}}\left(T_{\mathrm{wp}}-T_{\mathrm{die}}\right)$

$T_{\text {wp }}=$ local surface temperature of the workpiece

$T_{\text {die }}=$ local temperature of the tool

$\alpha_{\mathrm{tr}}=$ heat transmission coefficient

$\tau=$ cycle time

$n=$ number of the cycle

In this manner it is possible to simulate the temperature field and include the thermal dilatation of the dies for many forging cycles.

The heat flow into the upper and lower die and from there into the matrix was neglected. The different pressure dwell times of both drive units were taken into account. The simulations were done for the case of 60 strokes/min, every second stroke being a forging stroke. The calculated heat flow from the forging simulation was transferred for a total of 36 strokes on to the die.

The simulations were accomplished using the commercial FE package MSC.MARC. The starting temperature of the die was $100^{\circ} \mathrm{C}$. Figure 8 shows the simulated temperature distribution of both drive units. Already after 18 forging strokes (36 strokes), significant differences can be seen between the drive units. In the case of the non-circular gear drive unit, the maximum temperature reached approximately $460{ }^{\circ} \mathrm{C}$.

The highest temperature for the conventional drive unit was $780^{\circ} \mathrm{C}$. Owing to the shorter pressure dwell time of the non-circular gear drive unit, the amount of heat flow during the forging process was significantly lower than for the conventional drive unit. Furthermore, heat was conducted away more efficiently as a result of the longer cooling time.

\section{CONCLUSION}

This article describes how to optimize the design of noncircular gears used in press drives. The required symmetrical ram kinematics means that an eccentrically mounted circular driving gear can be used. Since this gear may be manufactured conventionally, a reduction in manufacturing costs may be possible in comparison with two non-circular gears.

The evolution of the temperature of the workpiece during the forging time can be simulated very easily with the uncoupled simulation tool described. This simulation tool is optimized to reduce the FE simulation time of complex three-dimensional problems. The results of these simulations have shown that the workpiece is hotter after the forging process using a press with noncircular gears. This can be very important for the integrated heat treatment. Nevertheless, the thermal die loading of this press is much lower than for the 


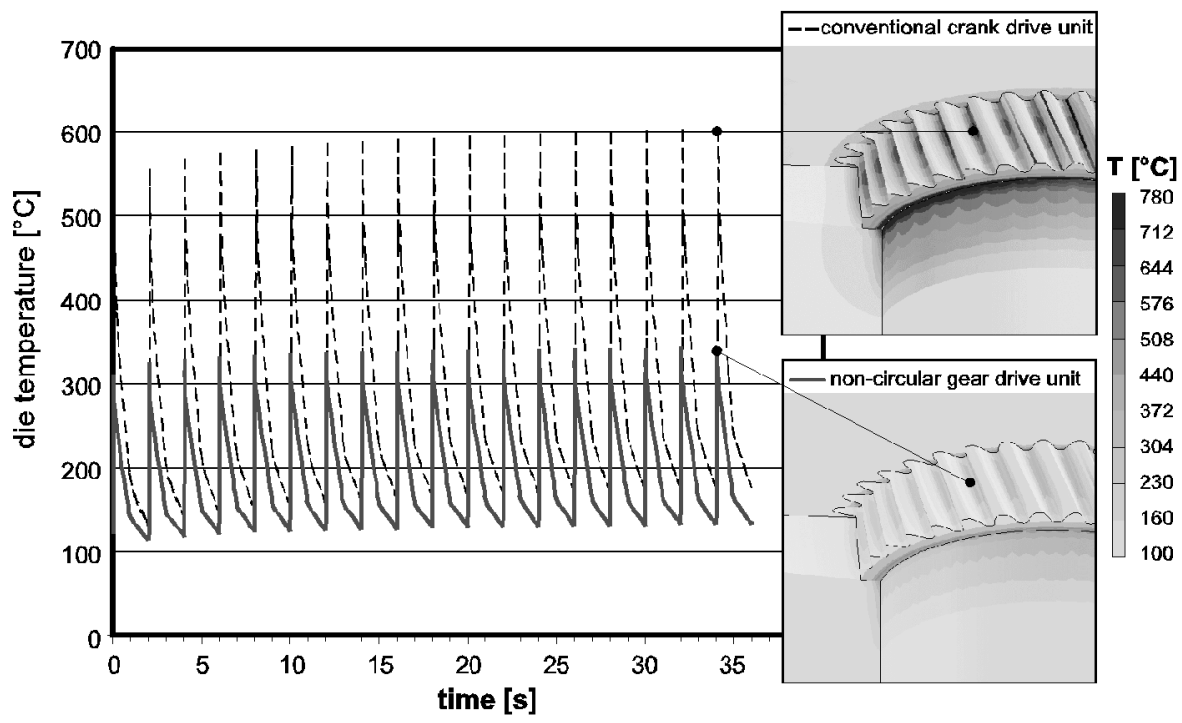

Fig. 8 Comparison of the temperature distribution in the toothed forging die after the 18 th forging stroke for both drive units

conventional press. Therefore, the thermal damage to the dies is smaller.

In contrast to the conventional press drive unit, the non-circular gear drive unit has the following advantages:

1. The pressure dwell time is reduced significantly.

2. The time for cooling and handling is longer.

3. The thermal die loading is lower.

4. The heat transfer from the workpiece into the dies is lower.

\section{ACKNOWLEDGEMENTS}

Parts of this examination have been conducted with support from the German Association of Machine Tool Builders (VDW) and have been sponsored by the German Ministry for Economy (BMWi) via the German Federation of Industrial Cooperative Research Associations 'Otto von Guericke' e.V. (AiF 11564 N).

\section{REFERENCES}

1 Tan, X. Development of precision forged gear technology in China. In International Conference on Forging and Related Technologies (ICFT'98), Birmingham, 28-29 April 1998, pp. 323-331.

2 Karkmann, A. and Lüdenbach, B. Endkonturnahes Fertigen der Innenform von Gleichlaufgelenkenkkörpern (Near net shape production of the internal contour of correcting hinges). Maschinenmarkt, Würzburg, 1997, 102(3), 24-27.
3 Dean, T. A. and Eyercioglu, Ö. Design and manufacture of precision gear forging dies. In International Conference and Exhibition on Design and Production of Dies and Molds, Istanbul, Turkey, 19-21 June 1997, pp. 311-316.

4 Schliephake, U. Analyse des Werkzeugverschleißes beim Gesenkschmieden (Analysis of die wear in drop forging). Fortschr.-Ber. VDI, Ser. 2, No. 306, VDI-Verlag, 1994.

5 Doege, E. and Hindersmann, M. Optimized kinematics of mechanical presses with non-circular gears. Ann. CIRP, 1997, 46(1).

6 Doege, E. and Bohnsack, R. Press concept for the future in precision forging. Advanced technology of plasticity. In Proceedings of 6th ICTP, Nuremberg, 19-24 September 1999, pp. 203-210.

7 Hasse, T. Verzahnungen für Unrundräder hoher Qualität (Gear teeth for high quality noncircular wheels. Layout and manufacturing by gear shaping). VDI-Z, 1990, 132(6), 55-59.

8 Litvin, F. L. Gear Geometry and Applied Theory, 1994 (Prentice-Hall, Englewood Cliffs, New Jersey).

9 Shen, S.-F. and Dawson, P. R. Simulation of materials processing: theory, methods and applications. In Proceedings of 5th International Conference on Numerical Methods in Industrial Forming Processes, NUMIFORM 95, 1995.

10 Geiger, M. Advanced technology of plasticity. In Proceedings of 6th ICTP, Nuremberg, 19-24 September 1999.

11 Owen, D. R. J. and Onate, E. Computational plasticity, fundamentals and applications. In Proceedings of 5th International Conference on Computational Plasticity, Barcelona, 1997.

12 Neubauer, I. and Rotarescu, M.-I. Entkoppelte Berechnung der Werkzeugbeanspruchung bei inkrementellen Umformverfahren (Uncoupled calculation of die loading in incremental processes). MARC Benutzertreffen, 28-29 October 1998, pp. 1-11. 